\title{
PROMOÇÃO DE SAÚDE MENTAL COM DOCENTES DA REDE PÚBLICA DE ENSINO: RELATO DE EXPERIÊNCIA
}

\author{
Tainá Maria Vidal Santos, Universidade Federal de Campina Grande (UFCG), \\ tainamaria.v@gmail.com \\ Maria Iasmin Lopes Ramalho, Universidade Federal de Campina Grande (UFCG), \\ iasminlopesramalho@gmail.com \\ Paula Frassinetti Oliveira Cezário, Universidade Federal de Campina Grande (UFCG), \\ paulafrassinetti22@gmail.com
}

\begin{abstract}
RESUMO
Atualmente a saúde física e mental dos professores representa uma das grandes preocupações da sociedade. As atividades laborais desenvolvidas por docentes favorecem o surgimento de insatisfação profissional e depressão, uma vez que os educadores são constantemente pressionados a desenvolver seu trabalho com qualidade, essas imposições sociais podem resultar no desgaste psicológico, emocional e físico. O presente estudo trata-se de um estudo descritivo do tipo relato de experiência, cujo objetivo foi apresentar e discutir um relato de experiência sobre a promoção de saúde mental, na qual foram abordadas temáticas sobre as psicopatologias mais comuns no ambiente de trabalho, destacando a síndrome de Burnout e a depressão. Diante dessa realidade vivenciada, compreendemos a importância de ações de saúde que enfoquem nas psicopatologias e a necessidade de promover ações de saúde mental voltadas principalmente para professores que vivenciam no seu cotidiano situações estressantes que podem resultar em sofrimento mental.
\end{abstract}

PALAVRAS-CHAVE: Depressão; Docentes; Síndrome de Burnout.

\section{PROMOTION OF MENTAL HEALTH WITH TEACHERS OF THE PUBLIC EDUCATION NETWORK: EXPERIENCE REPORT}

\begin{abstract}
Today, the physical and mental health of teachers represents one of the great concerns of society. Work activities developed by teachers favor the emergence of professional dissatisfaction and depression, since educators are constantly pressured to develop their work with quality, these social impositions can result in psychological, emotional and physical wasting. The present study is a descriptive study of the type of experience report, whose objective was to present and discuss an experience report about the promotion of mental health, in which the themes on the most common psychopathologies in the work environment were addressed, highlighting the Burnout syndrome and depression. Faced with this reality, we understand the importance of health actions that focus on psychopathologies and the need to promote mental health actions aimed primarily at teachers who experience stressful situations in their daily lives that can result in mental suffering.
\end{abstract}

KEYWORDS: Depression; Teachers; Burnout Syndrome. 


\section{PROMOCIÓN DE SALUD MENTAL CON DOCENTES DE LA RED PÚBLICA DE ENSEÑANZA: RELATO DE EXPERIENCIA \\ RESUMEN}

Actualmente, la salud física y mental de los profesores representa una de las grandes preocupaciones de la sociedad. Como actividades laborales desarrolladas por docentes favorecen el surgimiento de insatisfacción profesional y depresión, una vez que son educados y constantemente presionados para su trabajo con calidad, éstas pueden ser resultantes sin desgaste psicológico, emocional y físico. El presente estudio trata de un estudio descriptivo del tipo relato de experiencia, cuyo objetivo fue presentado y analizado un relato de experiencia sobre una promoción de salud mental, en la cual tuvo abordajes abordados sobre como psicopatologías más comunes en el ambiente de trabajo, destacando el Síndrome de Burnout y la depresión. Ante esta realidad vivenciada, comprendo la importancia de acciones de salud que abordan las psicopatologías y la necesidad de promover acciones de salud mental dirigidas principalmente a profesores que experimentan en su cotidiano situaciones estresantes que pueden resultar en sufrimiento mental.

PALABRAS CLAVES: Depresión; Docentes; Síndrome de Burnout.

\section{INTRODUÇÃO}

As mudanças na sociedade e no modo de vida das populações acabarão interferindo e refletindo na vivencia dos trabalhadores, fazendo com que eles se sintam mais cobrados com as exigências que aparecem em decorrência da demanda e de uma rotina rígida. É muito comum que as atividades profissionais sofram alterações dificultando assim a relação entre vida pessoal, que acabam por gerar desgastes de caráter físico e psicossocial, sendo estes os maiores responsáveis pelo aparecimento de diversas patologias. (Sousa \& Araújo, 2015)

Atualmente a saúde física e mental dos professores representa uma das grandes preocupações da sociedade. As atividades laborais desenvolvidas por docentes favorecem o surgimento de insatisfação profissional e depressão, uma vez que os educadores são constantemente pressionados a desenvolver seu trabalho com qualidade, essas imposições sociais podem resultar no desgaste psicológico, emocional e físico (Batista JBV, Carlotto MS, Oliveira MN et al,2016).

Segundo o estudo de Silva (2015) destacam-se alguns fatores que influenciam no adoecimento dos profissionais que trabalham na educação, podendo ser contemplados: as 
condições de trabalho precárias, salários baixos, salas de aula com excesso de alunos, violência, pressão dos pais e alunos, ansiedade. E em decorrência desses fatos estressantes, observou-se o aparecimento de consequências emocionais tais como: alteração no bem estar psicológico e qualidade de vida, relação com interações profissionais e descaracterização, além de efeitos físicos: alterações de funcionamento em órgãos que irão influenciar o sistema imune causando debilitação no mesmo (timo e gânglios linfáticos), como também o aumento do risco de infarto em decorrência do aumento do funcionamento da glândula suprarrenal.

O professor desempenha um papel fundamental no processo de formação da sociedade contribuindo para a formação de cidadãos críticos e reflexivos. Diante das responsabilidades e funções desenvolvidas pelos educadores, é necessário que os docentes estejam mentalmente saudáveis para executar suas capacidades pedagógicas e sociais (BATISTA et al,2016).

O presente estudo tem como objetivo apresentar e discutir um relato de experiência sobre a promoção de saúde mental, na qual foram abordadas temáticas sobre as psicopatologias mais comuns no ambiente de trabalho, destacando a síndrome de Burnout e a depressão, realizado com professores da rede pública de ensino.

\section{METODOLOGIA}

Trata-se de um estudo descritivo do tipo relato de experiência. Ação de promoção a saúde foi realizada com docentes de uma escola de ensino médio, para abordar temáticas sobre a saúde mental. Durante a realização da atividade de promoção de saúde mental utilizou-se como instrumento metodológico a exposição oral do conteúdo, através de vídeos e da roda de conversa, na qual foi estimulada a interação do grupo de docentes para debater as temáticas sobre a importância do cuidado com a saúde mental, realizaram-se esclarecimentos sobre os principais sinais, sintomas, diagnóstico e tratamento a síndrome de Burnout e a depressão.

\section{RESULTADOS E DISCUSSÕES}

A ação de promoção de saúde mental ocorreu em junho de 2017 em uma escola da rede pública de ensino, cuja mesma apresenta médio porte e está localizada no estado da Paraíba, participaram da ação 17 professores, desse total 4 lecionam a disciplina de matemática,1 português,1 química,1 história,3 geografia,2 inglês,1 espanhol,1 física,1 
biologia, 1 sociologia e 1 filosofia, em relação ao sexo 9 pertencem ao sexo feminino e 8 são do sexo masculino, o tempo de serviço como docentes dos indivíduos que participaram da ação oscila entre 2 e 38 anos, a carga horária semanal varia entre 20 e 40 horas. A atividade de promoção de saúde mental ocorreu em um espaço reservado para reuniões e foram convidados a participar da intervenção todos os docentes que se encontravam no ambiente escolar no período diurno.

Durante a realização da atividade de promoção de saúde mental utilizou-se como instrumento metodológico a exposição oral do conteúdo, através de vídeos eda roda de conversa, na qual foi estimulada a interação do grupo de docentes para debater as temáticas sobre a importância do cuidado com a saúde mental, realizou-se esclarecimentos sobre os principais sinais, sintomas, diagnóstico e tratamento a síndrome de Burnout e a depressão.

A Síndrome de Burnout conhecida também como síndrome do esgotamento profissional se inicia quando indivíduo passa a apresentar respostas em decorrência de diversos fatores ao qual foram expostos, como por exemplo, agentes estressores que são comuns no ambiente de trabalho, esgotamento profissional por excesso de carga horária, dentre outros fatores que irão interferir negativamente para o agravamento dessa situação. Vários são os sintomas de profissionais que apresentam essa síndrome, como a falta de entusiasmo e a exaustão, perca de interesse em certas atividades, alguns problemas físicos e sociais, repercutindo negativamente para a vida profissional e pessoal daquele indivíduo, dificultando assim o seu convívio familiar e também uma provável queda de produtividade. (KOGA, et al,2015).

A depressão é considerada um problema de saúde pública nos dias atuais, sendo responsável pela tristeza excessiva e na maioria dos casos o desfecho desse problema se torna o suicídio e que podem acometer desde pessoas jovens até pessoas com idades mais avançadas. (MARTINS, 2016)

Em um estudo realizado por Pereira (2017) com docentes, evidenciou-se que a maioria deles possuía características e sintomatologia que evidenciava a depressão, como a ansiedade, irritabilidade, desespero e pânico. A depressão nesses professores acontece em decorrência ao que é vivido dentro do ambiente escolar, onde o nível socioeconômico e o comportamento daqueles alunos irão ter uma relação intima a esse estresse profissional. E como consequência 
desse processo de adoecimento, os profissionais ficam fragilizados, decrescendo assim a sua produtividade e na maioria das vezes se sentem impulsionados a deixarem a sala de aula.

Durante a ação da promoção de saúde foi evidenciado através de relatos dos docentes alguns fatores de risco para o desenvolvimento da síndrome de Burnout e depressão que condizem com a literatura científica, dentre os quais podemos citar a carga horária de trabalho excessiva, as exigências constantes para o desenvolvimento de atividades laborais com qualidade, os conflitos com o alunado, estresse, sentimentos de tristeza, baixo auto-estima e pensamentos negativos em ralação a vida profissional e pessoal.

Dentre as propostas apresentadas para proporcional o bem estar biopsicossocial destacamos a realização de exercícios físicos, encorajamos a execução de atividades prazerosas e de lazer para os professores, informamos sobre a importância de buscar os serviços de saúde oferecidos pelo Sistema Único de Saúde (SUS) como a atenção básica e os centros de atenção psicossocial.

Atenção básica é considerada um serviço de saúde, na qual permite o primeiro contato com a comunidade, neste serviço de saúde são contempladas ações que visão promover, planejar, recuperar e habilitar os usuários, para que estas ações ocorram de forma efetiva é necessário ter parcerias entres os serviços de saúdes que são previstos pela rede, ou seja, quando atenção não consegue obtiver resolubilidade, há necessidade que o usuário passe por serviços especializados.

Segundo a portaria $\mathrm{n}^{\circ} 3.088$ de 2011 que institui a rede de atenção psicossocial define como responsabilidades da atenção básica a saúde mental a realização de ações de promoção, prevenção e cuidados com a saúde mental que proporcione a redução de danos causados por transtornos mentais, o uso de CRACK, álcool e outras drogas compartilhando o cuidado com os outros segmentos da rede de atenção psicossocial (BRASIL,2011).

Os CAPS (Centro de Atenção Psicossocial) surgiram com a finalidade de se ter a atenção à saúde mental no nível de atenção primária, facilitando assim o acesso, e procurando que os profissionais da atenção passassem a observar o paciente de uma óptica diferente, tendo uma visão holística do individuo identificando as fragilidades e possivelmente os problemas que o cliente venha a apresentar. Então os cuidados com a saúde mental podem alterar e apresentar melhorias na vida da população, não restringindo apenas ao cuidar e sim na prevenção de agravos, a fim de proporcionar uma melhoria de vida. (BRASIL, 2013) 


\section{CONSIDERAÇÕES FINAIS}

Diante dessa realidade vivenciada, compreendemos a importância de ações de saúde que enfoquem nas psicopatologias e a necessidade de promover ações de saúde mental voltadas principalmente para professores que vivenciam no seu cotidiano situações estressantes que podem resultar em sofrimento mental. As ações de promoção de saúde mental devem ser expandidas aos diversos setores da sociedade para que o cuidado com a saúde mental não seja oferecido apenas nas instituições de saúde, como também é fundamental que toda equipe de saúde esteja apta a promover discussões sobre psicopatologias e a reduzir o estigma que envolve os transtornos mentais.

Nesse contexto percebemos a importância e as contribuições da realização de ações de promoção de saúde executadas pelos discentes dos cursos da área da saúde durante a graduação, uma vez que isso irá contribuir para a formação de profissionais aptos a desenvolver intervenções sobre as diversas problemáticas de saúde pública que acometem a sociedade em geral.

O presente estudo apresenta algumas limitações em relação à quantidade de ações realizadas e o número reduzido de professores que participaram das atividades de promoção de saúde, uma vez que foram considerados apenas os docentes que se encontravam no ambiente escolar durante o período diurno, excluindo assim os demais educadores que trabalham nos turnos vespertino e noturno. No entanto os resultados alcançados durante a promoção de saúde mental demonstram as potencialidades desde expor e disseminar informações sobre o cuidado com a saúde mental contribuindo assim para a prevenção e o tratamento adequado de psicopatologias que possam acometer os docentes. Dessa forma sugerisse novos estudos que contemple as temáticas sobre o cuidado com a saúde mental dos professores desenvolvendo discussões sobre os fatores predisponentes que podem ocasionar danos ao bem estar biopsicossocial dos docentes.

\section{REFERÊNCIAS BIBLIOGRÁFICAS}

BATISTA, Jaqueline Brito Vidal et al. Transtornos mentais em professores universitários: estudo em um serviço de perícia médica Mental disorders in university teachers: study in a service of medical investigation. Revista de Pesquisa: Cuidado é Fundamental Online, 
[S.1.], v. 8, n. 2, p. 4538-4548, apr. 2016. ISSN 2175-5361. Disponível em: <http://www.seer.unirio.br/index.php/cuidadofundamental/article/view/5009>. Acesso em: 29 july 2017. doi:http://dx.doi.org/10.9789/2175-5361.2016.v8i2.4538-4548

BRASIL. Ministério da Saúde. Gabinete do Ministro. Portaria n³.088, de 23 de dezembro de 2011.Institui a Rede de Atenção Psicossocial para pessoas com sofrimento ou transtorno mental e com necessidades decorrentes do uso de crack, álcool e outras drogas, no âmbito do Sistema Único de Saúde (SUS). Diário Oficial da União da República Federativa do Brasil. Brasília, 23 dez.2011. Disponível em:http://bvsms.saude.gov.br/bvs/saudelegis/gm/2011/prt3088_23_12_2011_rep.html.Acesso :15 de jun. 2017.

Brasil. (2013). Ministério da Saúde. Saúde mental (Cadernos de atenção básica, Vol. 34). Brasília, DF: o autor. Acesso em 02 de Agosto de 2017

DIEHL, Liciane; MARIN, Angela Helena. Adoecimento mental em professores brasileiros: revisão sistemática da literatura. Est. Inter. Psicol., Londrina, v. 7, n. 2, p. 6485, dez. 2016. Disponível em $<$ http://pepsic.bvsalud.org/scielo.php?script=sci_arttext\&pid=S223664072016000200005\&lng=pt\&nrm=iso>. Acessos em 29 jul. 2017.

KOGA, Gustavo Kendy Camargo et al. Fatores associados a piores níveis na escala de Burnout em professores da educação básica. Cad. saúde colet. [online]. 2015, vol.23, n.3 [cited 2017-08-02], pp.268-275. Acesso em 02 de Agosto de 2017

MARTINS, Rosa Maria. A depressão no idoso. Millenium-Journal of Education, Technologies, and Health, n. 34, p. 119de-123, 2016.Acesso em 15 de Agosto de 2017.

PEREIRA, Marcelo Ricardo. De que hoje padecem os professores da Educação Básica?. Educ. rev., Curitiba, n. 64, p. 71-87, June 2017 . Available from 
$<$ http://www.scielo.br/scielo.php?script=sci_arttext\&pid=S0104-

$40602017000200071 \& \operatorname{lng}=\mathrm{en} \& n r m=\mathrm{iso}>$. access

on 15 Aug. 2017. http://dx.doi.org/10.1590/0104-4060.49815.

SILVA, Débora de Paula da; SILVA, Maria de Nazareth Rodrigues Malcher de Oliveira. O TRABALHADOR COM ESTRESSE E INTERVENÇÕES PARA O CUIDADO EM

SAÚDE. Trab. educ. saúde, Rio de Janeiro ， v. 13, supl. 1, p. 201-214， 2015 . Available from <http://www.scielo.br/scielo.php?script=sci_arttext\&pid=S1981-

$77462015000400201 \& \operatorname{lng}=e n \& n r m=$ iso $>$. access on 27 July 2017.

SOUSA, Viviane Ferro da Silva; ARAUJO, Tereza Cristina Cavalcanti Ferreira de. Estresse Ocupacional e Resiliência Entre Profissionais de Saúde. Psicol. cienc. prof., Brasília, v. 35, n. 3, p. 900-915, Sept. 2015 . Available from $<$ http://www.scielo.br/scielo.php?script=sci_arttext\&pid=S141498932015000300900\&lng=en\&nrm=iso>. access on 27 July 2017. 